\title{
Response to commentary by G. Petit and T. Anfodillo
}

\author{
Frederick C. Meinzer - Katherine A. McCulloh • \\ Barbara Lachenbruch • David R. Woodruff • \\ Daniel M. Johnson
}

Received: 8 November 2010/ Accepted: 24 November 2010/Published online: 21 December 2010

(C) Springer-Verlag (outside the USA) 2010

We thank G. Petit and T. Anfodillo for their comments on "The blind men and the elephant: the impact of context and scale in evaluating conflicts between plant hydraulic safety and efficiency" (Oecologia, 2010, 164:287-296). Our intent in this Concepts article was to present our personal perspectives on some of the key issues that should be considered in characterizing the hydraulic architecture of intact plants functioning under the dynamic conditions that prevail in the field. A comprehensive review of the field of plant hydraulic architecture would greatly exceed the space limitations for this journal. Petit and Anfodillo (2011) suggest that we did not discuss the impact of conduit tapering (the narrowing of xylem conduits from the bottom to the tops of trees) on the safety versus efficiency tradeoff. While we did not address this issue explicitly, we did show the consequences of this tapering in our first two figures. The positive relationship between conduit and stem diameter, which we refer to as the taper function in a previous paper (McCulloh et al. 2010), varies among species with different wood types. However, simply knowing the taper function of a species does not predict the functional properties of the wood. This disconnect is the result of changes in several factors, but mainly the number of conduits per $\mathrm{mm}^{2}$, which we refer to as the packing function. The relationship between this trait and conduit taper varies among wood types (McCulloh et al. 2010). The importance of packing function can be seen in our Fig. 2, which shows

F. C. Meinzer $(\bowtie) \cdot$ D. R. Woodruff · D. M. Johnson Forestry Sciences Laboratory, USDA Forest Service, 3200 SW Jefferson Way, Corvallis, OR 97331, USA e-mail: rick.meinzer@oregonstate.edu

K. A. McCulloh · B. Lachenbruch

Department of Wood Science and Engineering,

Oregon State University, Corvallis, OR 97331, USA that even when conduit diameters overlap, the hydraulic conductivity of stems from diverse species can be quite different. Thus, even if the relationship between conduit diameter and vulnerability to embolism were known, the nature of the safety versus efficiency trade-off and its potential consequences could not be evaluated without knowledge of the packing function and operating ranges of xylem tension in situ as influenced by biophysical traits such as capacitance. Instead of focusing on xylem anatomical features, which have been covered in detail elsewhere, we chose to address the consequences of these underlying traits for whole-plant hydraulic function. Only by understanding how these xylem structural features interact with xylem biophysical properties such as capacitance and conductivity can we fully appreciate how hydraulic architecture serves to maintain long-distance water transport under the dynamic conditions normally faced by plants.

\section{References}

McCulloh KA, Sperry JS, Lachenbruch B, Meinzer FC, Reich PB, Voelker S (2010) Moving water well: comparing hydraulic efficiency in twigs and trunks of coniferous, ring-porous, and diffuse-porous saplings from temperate and tropical forests. New Phytol 186:439-450

Petit G, Anfodillo T (2011) Comment on "The blind men and the elephant: the impact of context and scale in evaluating conflicts between plant hydraulic safety and efficiency" by Meinzer et al. (2010). Oecologia (in press) 